\title{
ATRIBUTOS AMBIENTAIS E DIRETRIZES PROJETUAIS EM QUARTOS DE INTERNAÇÃO PEDIÁTRICA
}

\author{
ATRIBUTOS AMBIENTALES Y DIRECTRICES DEL PROYECTO EN SALAS DE HOSPITALIZACIÓN \\ PEDIÁTRICA
}

ENVIRONMENTAL ATTRIBUTES AND PROJECT GUIDELINES IN PEDIATRIC HOSPITALIZATION ROOMS

\section{SCHMITT KERCHNER, ISABELA GUESSER}

Mestre em Arquitetura e Urbanismo, Universidade Federal de Santa Catarina. E-mail: isagschmitt@gmail.com

\author{
BINS ELY, VERA HELENA MORO \\ Doutora em Engenharia de Produção, Universidade Federal de Santa Catarina. E-mail: vera.binsely@gmail.com
}

\section{RESUMO}

Este trabalho parte da premissa que as características do ambiente impactam na saúde e influenciam no bem-estar e recuperação do paciente. Aborda um recorte de estudo de caso realizado em um hospital pediátrico, e tem como objetivo identificar quais atributos ambientais influenciam na percepção de bem-estar dos usuários durante a internação pediátrica. A pesquisa apresenta caráter qualitativo e adotou uma abordagem multimétodos, com o propósito de ampliar a visão do objeto de estudo e, ainda, obter resultados complementares. Os procedimentos metodológicos selecionados tiveram como objetivo avaliar o ambiente construído - a partir de visitas exploratórias, observação do comportamento e observação de traços físicos - e, obter a percepção dos usuários acerca do objeto de estudo por meio dos métodos de inquirição. Os dados obtidos por diferentes métodos possibilitaram análises em forma de textos, tabelas e fotografias, a partir de análise de conteúdo e matriz de descobertas, esta última com o intuito de sintetizar os resultados pelos diferentes métodos adotados. A partir dos métodos aplicados foi possível estabelecer a relação entre as características do ambiente e as necessidades dos diferentes usuários, respondendo ao objetivo da pesquisa: identificar os atributos ambientais que proporcionam humanização no ambiente físico. Além disso, a discussão dos resultados levou à proposição de diretrizes projetuais para a unidade de internação pediátrica segundo os princípios de humanização.

PALAVRAS-CHAVE: humanização; arquitetura hospitalar; internação pediátrica.

\section{RESUMEN}

Este trabajo se basa en la premisa de que las características del entorno impactan em la salud e influyen em el bienestar y la recuperación del paciente. Aborda un extracto de un estudio de caso realizado em un hospital pediátrico y tiene como objetivo identificar qué atributos ambientales influyen em la percepción del bienestar de los usuarios durante la hospitalización pediátrica. La investigación tiene un carácter cualitativo y adoptó un enfoque multimetodo, con el propósito de ampliar la visión del objeto de estudio y, aún así, obtener resultados complementarios. Los procedimientos metodológicos seleccionados tenían como objetivo evaluar el entorno construido, desde visitas exploratorias, observación del comportamiento y observación de rasgos físicos, y obtener la percepción de los usuarios de estudio a través de los métodos de investigación. Los datos obtenidos por diferentes métodos permitieron el análisis em forma de textos, tablas y fotografias, basados em análisis de contenido y una matriz de hallazgos, este último con el objetivo de sintetizar los resultados por los diferentes métodos adoptados. Con base en los métodos aplicados, fue posible establecer la relación entre las características del entorno y las necesidades de los diferentes usuarios, respondiendo al objetivo de la investigación: identificar los atributos ambientales que proporcionan la humanización en el entorno físico. Además, la discusión de los resultados condujo a la propuesta de pautas de diseño para la unidad de hospitalización pediátrica de acuerdo con los principios de la humanización.

PALABRAS CLAVES: humanización; arquitectura del hospital; hospitalización pediátrica.

\begin{abstract}
This work is based on the premise that the characteristics of the environment impact on health and influence the patient's well-being and recovery. It addresses an excerpt from a case study carried out in a pediatric hospital, and aims to identify which environmental attributes influence the perception of well-being of users during pediatric hospitalization. The research has a qualitative character and adopted a multi-method approach, with the purpose of broadening the view of the object of study and, still, obtaining complementary results. The selected methodological procedures aimed to assess the built environment - from exploratory visits, observation of behavior and observation of physical traits - and to obtain the users' perception of the object of study through the methods of inquiry. The data obtained by different methods allowed analysis in the form of texts, tables and photographs, based on content analysis and a matrix of findings, the latter with the aim of synthesizing the results by the different methods adopted. Based on the applied methods, it was possible to establish the relationship between the characteristics of the environment and the needs of different users, responding to the research objective: to identity the environmental attributes that provide humanization in the physical environment. In addition, the discussion of the results led to the proposal of design guidelines for the pediatric inpatient unit according to the principles of humanization.
\end{abstract}

KEYWORDS: humanization; hospital architecture; pediatric hospitalization.

Recebido em: 14/10/2020 Aceito em: 07/04/2021 


\section{INTRODUÇÃO}

Durante a internação pediátrica a criança e o adolescente são retirados de seu ambiente habitual, da sua casa e do convívio com familiares, interrompendo sua rotina diária. Essa abrupta mudança pode causar sentimentos de medo, insegurança e ansiedade. A hospitalização pediátrica se caracteriza como um eventual momento particular no desenvolvimento humano, acrescentando experiências à vivência infantil, impondo novos e inusitados eventos os quais a criança se vê obrigada a aprender a lidar (OLIVEIRA; DIAS; ROAZZI, 2003). O ambiente hospitalar é, dessa forma, muitas vezes hostil, havendo poucos elementos com os quais a criança possa se identificar.

Ambientes de uso institucional, como no caso de hospitais, em geral possuem espaços padronizados, que aliado a falta de recursos financeiros, baixa qualidade das construções e pouca manutenção resultam em ambientes (locais) onde os conceitos de humanização ficam, muitas vezes, em segundo plano. Ulrich (2001) em seus estudos sobre o impacto do ambiente no bem-estar físico e psicológico dos usuários, demonstra que um ambiente humanizado gera benefícios para o paciente, seus acompanhantes e também para o corpo técnico, podendo diminuir os níveis de estresse, ansiedade, depressão, e até mesmo o tempo de internação.

Esta pesquisa propõe avaliar os ambientes dos quartos de internação pediátrica, a partir de um estudo de caso em um hospital público. Sabendo que a legislação atual aborda a questão arquitetônica prioritariamente nos aspectos quantitativos (como por exemplo, as dimensões do ambiente versus a população), este estudo busca justamente avaliar o ambiente construído em seus aspectos qualitativos, levando em consideração critérios como humanização, comportamento socioespacial humano e percepção do usuário.

\section{MÉTODO}

Este estudo foi abordado de forma qualitativa, por compreender que os resultados esperados não consistem em valores estatísticos e tabulados, e sim na análise de diferentes variáveis e condicionantes que influenciam nas relações dos indivíduos com o ambiente construído. Na pesquisa de campo - sob a forma de estudo de caso - buscou-se compreender os aspectos construtivos, funcionais, comportamentais e também obter a percepção dos usuários acerca do espaço. Para isso, foi adotada uma abordagem interdisciplinar e multimétodos, com o intuito de ampliar a visão do objeto de estudo para obtenção de resultados complementares. O estudo de caso único ocorreu no Hospital Infantil Joana de Gusmão em Florianópolis/SC, considerado representativo para alcançar os objetivos da pesquisa, tanto pela sua estrutura física como no suporte ao atendimento a diferentes faixas etárias e especialidades clínicas. Foram selecionados para análise seis tipologias de quartos de internação, definidos a partir de critérios relacionados à arquitetura: número de leitos por quarto, área total, características do banheiro do paciente (uso exclusivo ou compartilhado), orientação solar e a relação interior versus exterior. Os quartos analisados apresentam variações de três e quatro leitos, distribuídos em três unidades de internação.

\section{Participantes}

Esta pesquisa buscou investigar a percepção dos principais usuários do espaço sobre o ambiente construído; dessa forma, nas entrevistas foram incluídos os profissionais da saúde, os acompanhantes e os pacientes. Dentre os profissionais da saúde foram entrevistados: o enfermeiro chefe de cada unidade e os técnicos de enfermagem, pois são os que possuem contato direto com o paciente, sendo o ambiente analisado também seu ambiente de trabalho. Também foram entrevistados os acompanhantes dos pacientes das três unidades de internação e o critério de seleção dos pacientes envolveu a definição de uma faixa etária mínima para participação. A idade mínima foi definida através de entrevista piloto, onde foi observado a capacidade dos pacientes em verbalizar, comunicar e expressar sua opinião, atendendo as expectativas da aplicação do método. Dessa forma, a faixa etária dos pacientes considerada para este estudo foi entre cinco e quinze anos. Ao todo foi obtida uma amostra de 32 entrevistados, sendo estes: 10 funcionários, 10 acompanhantes e 12 pacientes. Apesar da amostra limitada, esta foi considerada representativa para os objetivos desta pesquisa, pois observou-se que as respostas (opinião dos participantes) pouco variaram. Além disso, destaca-se que a amostra representa um recorte geográfico e cultural de usuários da Região Metropolitana de Florianópolis e, em menor proporção, de outras regiões do Estado. A investigação foi submetida ao Comitê de Ética de Pesquisa com Seres Humanos vinculados à Universidade Federal de Santa Catarina e ao Hospital Infantil Joana de Gusmão, e aprovada no processo CAAE nº 02616818.2.3001.5361 em 18/03/2019. 


\section{Métodos de pesquisa}

Na pesquisa de campo foram escolhidos métodos com o intuito de responder a dois objetivos: efetuar a leitura do ambiente construído (etapa 1) sob a percepção da pesquisadora; e obter a percepção dos usuários (etapa 2). Na leitura do ambiente construído foram combinados diferentes métodos: visita exploratória, observação do comportamento e observação dos traços físicos. E para intermediar o contato com os usuários foram aplicados métodos de inquirição, com diferentes abordagens conforme do tipo de participante.

O primeiro método aplicado foram as visitas exploratórias, sendo preenchidas as planilhas de avaliação dos ambientes, desenvolvidas pelo pesquisador. Nesse instrumento, foram identificados aspectos relevantes para pesquisa - embasados no referencial teórico - e combinados com croquis e fotografias. Características ambientais - tais como materiais e acabamentos, elementos decorativos, mobiliário, equipamentos, aberturas, iluminação, ventilação, conforto térmico, conforto acústico, aromas - foram caracterizados como positivo ou negativo, seguidos de uma descrição e eventuais observações adicionais. Além das características descritas acima, foram incluídos os componentes de humanização, que correspondem aos atributos ambientais que ajudam na redução do estresse e melhoria do bem-estar e saúde dos pacientes, que são: controle do ambiente, suporte social e distrações positivas (ULRICH, 1995). Nesta pesquisa foi incluído mais um componente, o de suporte às atividades (TISSOT, 2016). O controle do ambiente corresponde a uma maior autonomia do usuário no espaço (exemplo: controle da iluminação do quarto). O suporte social está presente nas relações benéficas do contato entre familiares e pacientes no ambiente hospitalar, promovida pelo ambiente físico (exemplo: jardins internos). As distrações positivas consistem nos estímulos presentes no ambiente que proporcionam pensamentos positivos, distrações e lazer (exemplo: vista para cenas da natureza). E o suporte às atividades é um componente que indica que o espaço necessita de ajustes para melhor funcionalidade para realização das atividades pelos usuários (exemplo: biombos).

Após levantamento das características físicas dos ambientes foram registrados o comportamento dos usuários (ZEISEL, 2006) e os traços físicos deixados pelos mesmos. Para sistematizar essas observações foi elaborada uma ficha, baseada em um instrumento existente (CAVALCANTI, 2011). É importante destacar que a presença da pesquisadora foi reconhecida pelos usuários, e para evitar possíveis desconfortos, foi limitada a permanência ao máximo 15 minutos por dia em cada ambiente. Além disso, as anotações foram preenchidas em ficha única - com espaço específico para cada método - para otimização do tempo. Durante a aplicação do método de observação do comportamento foram registrados e identificados os usuários do espaço (corpo técnico, acompanhante, paciente ou visita), por sexo, idade e posição (sentado, em pé, deitado ou caminhando). Além disso, foi demarcada a posição do observador e as atividades desempenhadas por cada um dos usuários.

O método de observação dos traços físicos (ZEISEL, 2006) foi aplicado para complementar as informações acerca do ambiente construído, compreender quais são as necessidades e dificuldades impostas pelo ambiente, bem como a forma como os usuários se comportam nos espaços. Esse método possui como objetivo procurar no espaço físico vestígios de atividades realizadas pelos usuários de forma consciente ou inconsciente. É importante destacar que para aplicação desse método não é necessária a presença dos usuários, logo tem caráter menos intrusivo.

$\mathrm{Na}$ etapa 2 da pesquisa de campo foram aplicados os métodos de inquirição. Para intermediar o relato dos usuários foi escolhida a entrevista semiestruturada para o público adulto e, para o público pediátrico, utilizouse a seleção visual (SANOFF, 1991). Um roteiro pré-estabelecido serviu de guia durante a interlocução com os adultos, incluindo questões gerais sobre o funcionamento, organização, rotina dos funcionários e dos pacientes, e também as percepções sobre o ambiente construído. O roteiro de perguntas incluía questões abertas e em umas destas questões foi aplicado o instrumento de mapeamento visual (THORNE, 1995). Os entrevistados demarcavam em planta baixa já desenhada pelo pesquisador os aspectos considerados negativos e positivos do ambiente. Essa abordagem permitiu um maior entendimento do ambiente pelo participante, facilitando sua resposta sobre a percepção do ambiente físico.

Com os pacientes internados buscou-se um instrumento com uma abordagem lúdica, de forma a amenizar a situação vivenciada no hospital e facilitar a verbalização. O instrumento aplicado foi a seleção visual: a partir de imagens pré-selecionadas pelo pesquisador promove-se uma reflexão e discussão sobre temas de interesse da pesquisa (SANOFF, 1991), nesse caso o quarto de internação. Foram selecionadas dez imagens, que apresentavam características distintas, por exemplo: quarto individual e quarto coletivo, cores quentes e cores frias, presença de diferentes mobiliários e mobiliário reduzido/compacto, diferentes relações com o exterior, presença de equipamentos eletrônicos, possibilidade de maior controle sobre o ambiente, privacidade, personalização, dentre outras características. A aplicação do método teve início com a distribuição das imagens para o paciente, em seguida foi solicitado que ele escolhesse as imagens preferidas e colasse um adesivo verde e um adesivo laranja nas imagens que havia ou não gostado, respectivamente. Após a seleção das imagens foi solicitado ao participante explicar os motivos de suas escolhas. 
Os métodos utilizados forneceram dados que possibilitaram análises textuais, em forma de tabelas e fotografias, adotando abordagens quantitativa e qualitativa. $\mathrm{Na}$ etapa 1 foram aplicadas as visitas exploratórias e observação do ambiente, sintetizados em forma de tabelas e análises textuais. Para a análise dos dados da etapa 2 - inquirição - foi utilizada análise de conteúdo (BARDIN, 2011), onde foram tratadas as informações das entrevistas.

\section{RESULTADOS E DISCUSSÃO}

O cruzamento dos resultados dos diferentes métodos (etapas 1 e 2) resultou na elaboração de uma matriz de descobertas. Essa forma de registro das informações é bastante visual, pois possibilita uma visão panorâmica do ambiente analisado, ressaltando seus principais problemas e qualidades (RHEINGANTZ et. al., 2009). Para discutir os resultados do estudo de caso é apresentada a matriz de descobertas, que proporciona a visualização dos resultados obtidos nos diferentes métodos aplicados (percepção da pesquisadora e dos usuários do espaço).

A matriz foi estruturada a partir da confirmação dos resultados obtidos pela abordagem multimétodos: avaliação do ambiente pela pesquisadora, observação do comportamento, observação dos traços físicos e as entrevistas. Em geral a forma de apresentação de uma matriz de descobertas é no formato de planta baixa, nesta pesquisa optou-se pelo formato de tabela, como forma de compilação dos dados dos seis quartos de internação. Os itens analisados foram agrupados por componentes de humanização, esta classificação permitiu o tratamento dos dados por categorias de análise: controle do ambiente (Tabela 1), distrações positivas (Tabela 2), suporte social (Tabela 3) e suporte às atividades (Tabela 4), na sequência de cada uma das tabelas são discutidos os resultados. As tabelas foram estruturadas em cinco colunas: na primeira coluna é identificado o componente de humanização e o elemento observado; a segunda e a terceira colunas correspondem a imagens ilustrativas e exemplos em planta baixa. A quarta coluna apresenta os resultados obtidos pela percepção da pesquisadora e a última coluna a percepção dos usuários. Os elementos destacados na matriz de descobertas foram os que obtiveram uma maior frequência nos relatos, apontando para os atributos que são essenciais para qualidade dos ambientes segundo seus usuários, identificados pela seguinte legenda: $(F)$ funcionários, $(P)$ acompanhantes, $(C)$ crianças e $(A)$ adolescentes.

Tabela 1: Matriz de descobertas - Controle do Ambiente.



CONTROLE DO AMBIENTE

Regulagem do leito
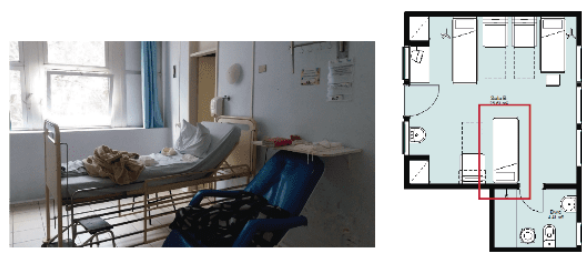

Cama infantil possui mecanismo manual e estrutura pesada que dificulta seu manuseio. Além disso, necess de manutenção pois apresenta partes enferrujadas e sem pintura.

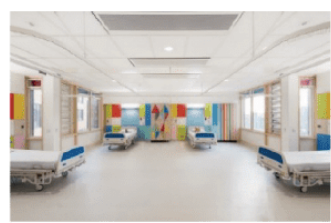

“O que não me agrada muito são as camas (...) mal tu consegue erguer as grades, tu sofre muito, (...) porque elas são muito velhas, enferrujadas, muito difícil. Então tu pensa pela segurança da criança de erguer as grades, mas tu pensa eu vou sofrer durante dias e dias." P08

"Acredito que pra uma criança do tamanho dela é um leito muito pequeno, mínimo. É muito estreito (...) eu fico incomodada pelo desconforto dela." P01

"Gostei porque é espaçoso e as camas devem ser confortáveis." $\mathrm{CO} 2$ 
Schmitt Kerchner, I. G; Bins Ely, V. H. M.

\section{CONTROLE DO AMBIENTE}

Privacidade | Acústica


CONTROLE DO AMBIENTE

Iluminação natural



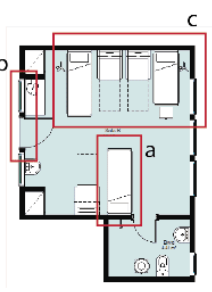

c Busca de privacidade através do cobertor, que cria uma barreira visual (territorialidade)e personaliza o ambiente. (a)

Para controle da privacidade foram instaladas cortinas nos vidros fixos voltados para o corredor, porém, verificou-se que as portas dos quartos permanecem sempre abertas, e os ruídos vindos do corredor e outros dos quartos se dissipam. (b)

Não existem barreiras físicas entre os leitos (privacidade), em algumas situações as dimensões reduzidas do espaço geram a sensação de aglomeração e há uma invasão do espaço pessoal do outro pela proximidade física. (c)



"Com a porta fechada não entra tanto barulho, mas com ela aberta entra bastante." P05

"Ponto negativo o ar condicionado que faz muito barulho, ficou bem em cima da nossa cabeça, é um ar condicionado muito antigo, faz bastante barulho mas gela bem." P08

"Quem sabe até uma divisão, se pudesse, pra te um pouco mais de privacidade. Até durante o dia a gente passa bem, mas de noite, às vezes tem um procedimento com os colegas do lado, aquele entra e sai, e acaba perdendo o sono." P03

"Quando a gente quer trocar de roupa, tem a cortina, achei isso muito certo." C01 r

\section{CONTROLE DO AMBIENTE}

Iluminação individual do leito



As cortinas regulam a passagem da luz; não existem elementos arquitetônicos como brises ou proteção externa. (a)

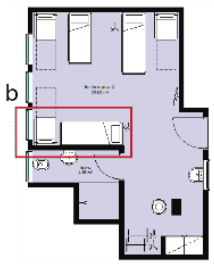

Verificou-se que o manuseio das janelas é dificultado pelas dimensões da folha e peso da estrutura. (a)

A organização do layout dificulta o manuseio da cortina por todos os ocupantes. Alguns leitos

estão dispostos próximos das janelas, fazendo com que

esse controle fique mais restrito (territorialidade), e

relacione a uma invasão do espaço pessoal do outro. (b)
"Eu não sei se é as janelas ou essas grades, se é muito fechado, nas outras a gente já viu bichinho e aranha." P07

"Eu gosto das janelas, por causa da claridade, o dia todo. As camas também, uma localizada em cada canto." (Quarto C) FO4

"O negativo é que não tem cortina suficient pra todas as janelas, tem o poste, tem o sol e acaba entrando." P06
CONTROLE DO AMBIENTE $\otimes$ DISTRAÇÃO POSITIVA

Acústica | Relação com o exterior | Cheiros externos
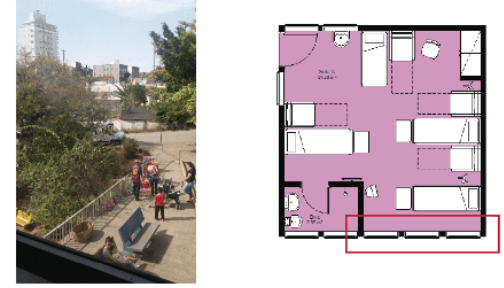

Iluminação individual através de arandela, com acionamento próximo do leito (territorialidade).

Não há como bloquear a luminosidade da arandela do leito vizinho (territorialidade).
"Tem uma luzinha pra cada cama, isso também ajuda." P06

\section{CONTROLE DO AMBIENTE $\mathbf{X}$. DISTRAÇÃO POSITIVA}
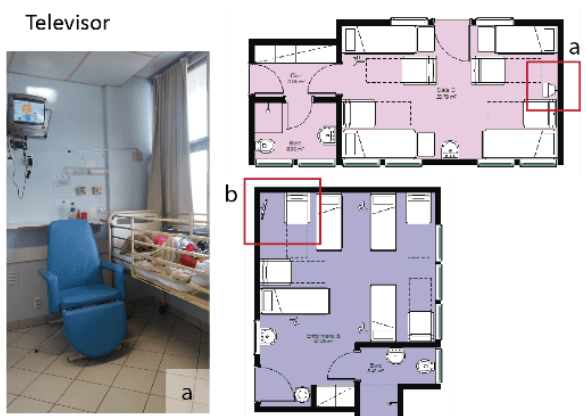

O uso do televisor é compartilhado, o usuário que detém o controle é quem define o canal e o volume (territorialidade), os demais usuários são obrigados a escutar o canal escolhido (privacidade). (b)
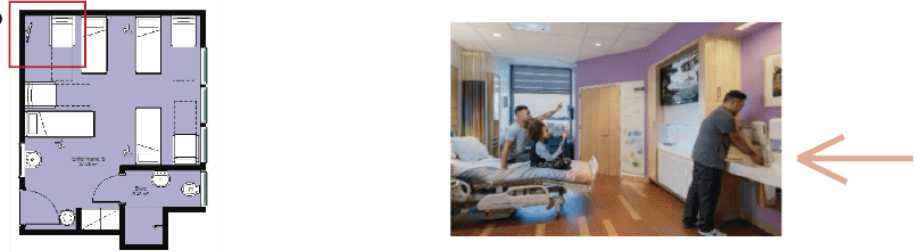

Os quartos da Unidade D estão voltados para a entrada do ambulatório, os sons vindo da rua e o movimento Em outros momentos, onde se requer maior silêncio, pode gerar desconforto e estresse, pelos cheiros e ruídos externos.
"Eu acho que outro ponto negativo é o barulho que começa aqui muito cedo, por exemplo, hoje começou pelas $4 \mathrm{~h}$ da manhã (...) eu acordo muito cedo e no começo do dia já tem várias pessoas lá embaixo, tem muitas crianças que choram, é lotado ali (sobre ambulatório)." P08

"Tem uma coisa aqui que é ruim, que as pessoas fumam nessa janela, que lá embaixo é o ambulatório e vira e mexe a gente tem que tá ligando que parece que estão fumando dentro do quarto." F06

"Eu acho assim que compartilhar um espaço não é fácil né, às vezes tem reclamação do tipo, um quer ver TV até tal hora e o outro quer dormir, outro quer ver um filme, uma criança tá chorando, então eu acho que compartilhar o espaço com 4, são 8 pessoas que compartilham no mínimo né." F06

"No meu caso aqui a TV por causa do som, que fica bem embaixo mesmo." P06

"Esse daqui por causa da janela, tem a TV bem grande." A03

Fonte: Elaborado pela autora 
Segundo Ulrich (1995) as pessoas sentem uma forte necessidade de controlarem o espaço e situações. Dessa forma, a perda do controle do ambiente pode acarretar no aumento dos níveis de estresse e ansiedade dos usuários. Verificou-se que em quartos de uso compartilhado, por exemplo, é mais difícil obter esse tipo de controle. No estudo de caso a categoria controle do ambiente foi a mais citada, principalmente a questão da privacidade e dos ruídos. A privacidade é uma forma de controle seletivo de acesso ao indivíduo, funcionando como um regulador de interação social e de informação e pode ser obtida a partir do ambiente construído: paredes, biombos, cortinas e isolamento acústico. Porém, em ambientes que não possibilitam o controle sobre a privacidade pode gerar estresse ao indivíduo. Ainda de acordo com o autor, a falta de controle da privacidade é um elemento que impacta na saúde do paciente, e está associada a alterações dos níveis de estresse (ULRICH, 2006). A presença de algum tipo de divisória entre os leitos foi percebida como uma oportunidade de maior isolamento e sensação de bem-estar, podendo até melhorar a qualidade do sono: "Quem sabe até uma divisão, se pudesse, pra ter um pouco mais de privacidade. Até durante o dia a gente passa bem, mas de noite, às vezes tem um procedimento com os colegas do lado, aquele entra e sai, e acaba perdendo o sono." (P03)

Os ruídos também podem se tornar uma fonte causadora de estresse nos ambientes hospitalares, os quais podem ser gerados pelos próprios usuários, pelos equipamentos e ou ser externos. Algumas medidas que podem amenizar a propagação dos ruídos são: criação de barreiras que ajudem no isolamento acústico e também numa implantação no terreno que considere o contexto do entorno do hospital, por exemplo. Evidências tem demonstrado que nos quartos de uso coletivo não há um controle efetivo sobre o ruído gerado pelos pacientes, e que quartos individuais são melhores por permitirem maior privacidade e menor influência dos ruídos internos (ULRICH, 2006). Além do tipo de ocupação do quarto, outro aspecto foi levantado no estudo de caso: a relação entre a localização dos quartos e as fontes externas de ruídos. Nos quartos localizados próximos ao ambulatório e emergência foi identificado que nos momentos onde se requer maior silêncio, como por exemplo durante o sono noturno ou nos descansos diurnos, os ruídos externos afetam negativamente os usuários, apesar da movimentação de pessoas também ter sido considerada uma fonte de distração positiva.

A iluminação também foi apontada como um elemento muito importante, principalmente a presença de iluminação natural, corroborando com as evidências que comprovam os efeitos positivos na qualidade do sono, ciclo circadiano, depressão, maior satisfação, menor tempo de internação e percepção do dia, da noite e do clima (ULRICH, 2006; VASCONCELOS, 2004). Para isso, um importante fator é a localização dos quartos de internação em relação a orientação solar, preferencialmente na orientação leste e norte (no caso de Florianópolis, embota tal condição possa ser diferente em outras localidades). Além da orientação solar privilegiada, para maior conforto térmico e lumínico é essencial que sejam previstas/adotadas medidas de proteção solar, como brises, marquises, cobogós, cortinas etc. A iluminação artificial foi outro fator destacado pelos entrevistados, principalmente a presença de iluminação individual no leito. A iluminação deve atender as diferentes necessidades e atividades realizadas no quarto de internação, sendo destacados os exames, 0 repouso, o lazer e a vigília (CALVACANTI, 2002). Dessa forma, quando os mecanismos de controle da iluminação não são eficientes eles podem ter o efeito reverso, como pode ser observado no relato: "O negativo é que não tem cortina suficiente para todas as janelas, tem o poste, tem o sol e acaba entrando" (P06).

A possibilidade de regulagem do leito também está associada a um tipo de controle do ambiente, pois influencia no conforto físico e bem-estar dos pacientes. No estudo de caso verificou-se que o mecanismo manual e estrutura pesada das macas dificulta o manuseio, fazendo com que a regulagem seja evitada. Outro elemento que refletiu bastante na satisfação dos usuários foi a relação entre as dimensões do ambiente e a livre circulação. $O$ deslocamento no ambiente também pode ser classificado como um controle do ambiente e está intimamente relacionado com as dimensões do ambiente e sua organização espacial. A falta de espaço físico nas circulações, por exemplo, pode gerar desconforto aos pacientes que não conseguem acessar sem interferências o banheiro e os armários e, aos funcionários que não conseguem ter livre acesso ao paciente, dificultando os procedimentos realizados no leito. O critério de circulação adequada também foi inferido por Rocha (2010) em sua dissertação como um importante elemento relacionado à arquitetura, e que impacta principalmente sobre o suporte social. Além disso, o dimensionamento e layout adequados também estão relacionados ao Suporte às Atividades, podendo interferir na realização das tarefas e atividades pelos usuários. 
Tabela 2: Matriz de descobertas - Distrações Positivas.

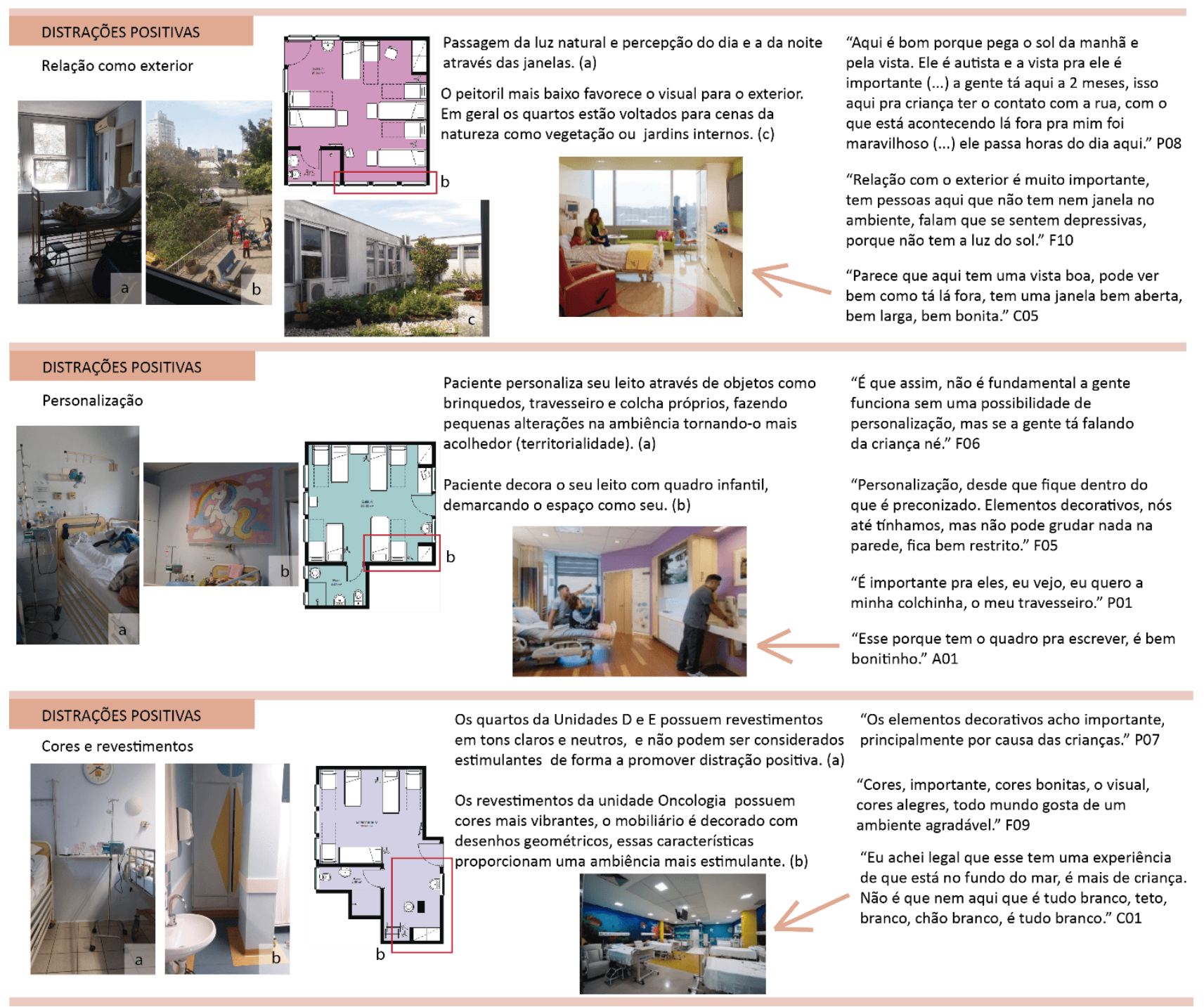

Fonte: Elaborado pela autora.

O segundo componente de humanização bastante citado pelos usuários, principalmente os acompanhantes e pacientes, são as distrações positivas. As distrações positivas consistem em estímulos presentes no ambiente que provocam sentimentos positivos nos usuários, que auxiliam na recuperação dos pacientes, tendo como reflexo uma ambiência mais acolhedora e agradável. A relação com o exterior demonstrou ser muito importante para os entrevistados, principalmente para os pacientes, que relacionaram as grandes aberturas e contato com o exterior com a possibilidade de observar o que acontece lá fora, servindo de distração positiva, corroborando com Vasconcelos (2004, p. 154) que afirma que "pacientes tem preferência por ambientes que proporcionam visualização de paisagens agradáveis e contato físico com o ambiente externo". Os quartos avaliados continham visuais para cenas da natureza, tanto os quartos voltados para o exterior como os voltados para os jardins internos, destaca-se que a presença de elementos naturais é muito eficiente como restauração do estresse e recuperação do paciente. Segundo Felippe (2015), os pacientes com vista para cenas da natureza consideraram seus quartos mais relaxantes que os pacientes com vista para cenas predominantemente construídas. Além disso, verificou-se a importância dos espaços abertos e em contato com a natureza para os pacientes pediátricos, que possibilitam movimentação, interação social e brincadeiras: "A gente usa bastante, tanto essa sala aqui, quanto a parte de recreação do hospital que é lá fora: a área do sol. A maior parte do tempo a gente tá circulando ou tá na rua, porque ela não gosta muito de ficar em ambiente fechado." (P07)

Outro elemento que foi citado como eficaz na distração dos pacientes é a presença de televisor nos quartos. Grande parte dos entrevistados relataram assistirem televisão como uma forma de passar o tempo e se distrair. A importância desse recurso ficou bastante evidente durante a aplicação da seleção visual com os 
pacientes, pois esse era um item frequentemente observado nas imagens. No entanto, os recursos audiovisuais podem ser considerados negativos quando os mecanismos de controle não são eficientes. Esse cuidado é necessário principalmente em quartos de uso compartilhado, visto que há diversidade no estado que cada paciente pode apresentar. A falta de controle dos canais e volume do televisor foi citada como aspecto negativo pelos entrevistados; de acordo com Felippe (2015) essa falta de controle faz com que estímulos antes positivos passem a ser indesejáveis e estressantes. O ideal nesta situação seria haver um televisor individual para cada paciente, e contar com fones de ouvido.

Nos relatos dos acompanhantes e funcionários o elemento cor não foi associado como essencial para qualidade do ambiente, porém, nas falas dos pacientes identificou-se que as cores e os revestimentos são muito importantes para a sensação de bem-estar e de pertencimento ao ambiente. As imagens em que os revestimentos eram coloridos (numa mistura de cores quentes e cores frias), eram consideradas mais estimulantes do que os quartos que continham apenas uma tonalidade, associados à monotonia e ao desânimo. Segundo Neufert (2008) as cores podem transmitir sensações variadas e efeitos tanto estimulantes como calmantes, de acordo com a tonalidade adotada. Numa pesquisa em que foi considerada a participação dos pacientes pediátricos na escolha do tema e da cor da unidade, Coad e Coad (2008) tiveram como resultado a preferência por tons de azul, laranja, rosa e amarelo, e pela combinação entre essas cores, apontando a importância da escolha da cor e da possibilidade de personalizar o ambiente como significativas na promoção da saúde.

A atividade de personalizar o espaço pode ser classificada como uma distração positiva, pois está relacionada a sentimentos de bem-estar e diminuição dos níveis de estresse, embora a possibilidade de personalização nos ambientes hospitalares seja mais restrita em função do risco de infecção hospitalar. No caso em estudo, observou-se que o ato de personalizar o local contribui para a sensação de pertencimento ao lugar e melhora dos níveis de satisfação: "É importante pra eles, eu vejo, eu quero a minha colchinha, o meu travesseiro" (P01). Bergan et al. (2009) acrescentam que quando o espaço é projetado para as crianças, a hospitalização pode ser percebida de forma mais positiva. A presença de brinquedos também foi identificada como outro elemento importante e que contribui para o controle da ansiedade dos pacientes, favorecendo sua adaptação ao ambiente hospitalar. Além de distraírem positivamente os pacientes, os brinquedos trazem calma e segurança (SILVA; CÔRREA, 2010) e, em alguns casos podem até ser utilizados como instrumentos de intervenção terapêutica, principalmente para pacientes mais jovens, justamente por facilitar a compreensão dos procedimentos e tornar a rotina mais amena.

Tabela 3: Matriz de descobertas - Suporte Social.



Fonte: Elaborado pela autora.

O suporte social também é uma fonte de distração positiva e de muita importância para recuperação dos pacientes, principalmente a presença da família. Observou-se, ainda, que a possibilidade de interação com outros pacientes também tem reflexo bastante positivo e foi um dos principais motivos pela preferência dos pacientes por quartos coletivos: "Esse daqui porque cabe bastante gente, tipo aqui (...) agora eu não posso levantar, mas antes eu ficava jogando com uma menina, jogando uno com ela, e dominó também." (C05) Esse relato confirma a necessidade de o ambiente colaborar com esse tipo de interação, de maneira a promover o contato social. No estudo de caso constatou-se que os quartos não apresentam mobiliário e espaço adequado para receber as visitas, porém, a área do sol (espaço ao ar livre) é bastante utilizada, pois cria oportunidades para os pacientes se envolverem em alguma atividade com a família num espaço mais agradável. Rollins (2009) destaca que a arquitetura deve proporcionar interação social e privacidade aos pacientes e suas famílias, e que os ambientes abertos e de uso coletivo como as brinquedotecas, sala de estar e enfermarias conjuntas, parecem fomentar a interação social. 
Tabela 4: Matriz de descobertas - Suporte às Atividades.

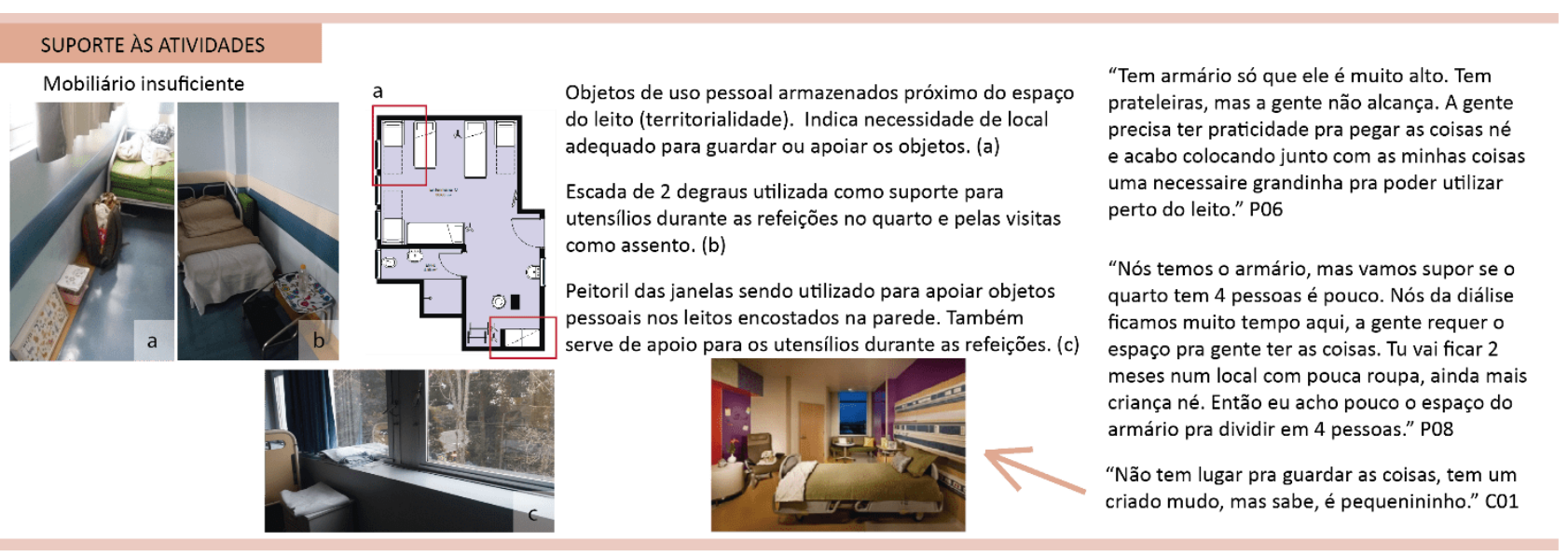

Fonte: Elaborado pela autora.

O componente de suporte às atividades foi mencionado com maior frequência pelos funcionários e está relacionado ao bom funcionamento dos ambientes, que considera a dimensão, forma, equipamentos, mobiliário e fluxos para a realização das atividades com conforto e segurança (TISSOT, 2016). Dessa forma, é muito importante que as dimensões do espaço e a organização espacial sejam compatíveis ao número e diversidade de usuários. No estudo de caso foi identificado que o mobiliário existente não colabora para realização de algumas atividades: falta de mobiliário de apoio para procedimentos no leito pelos funcionários, mobiliário insuficiente para guardar os pertences dos acompanhantes e pacientes e falta de mobiliário para realizar as refeições no quarto.

Além disso, observou-se incompatibilidade no dimensionamento dos banheiros, pois grande parte dos pacientes necessita de ajuda e o espaço não prevê a presença de cadeira de rodas e de outras pessoas auxiliando nos cuidados de higiene no box do chuveiro, por exemplo. Dessa forma, quando o ambiente não atende com conforto e segurança todas as atividades, podem ser gerados constrangimentos e insatisfação pelos usuários e, por isso, o suporte às atividades é um importante componente de humanização (TISSOT, 2016). Observou-se que o layout interfere diretamente na realização das atividades, e que o suporte às atividades foi o elemento mais significativo destacado pelos funcionários.

Os resultados obtidos nesta pesquisa indicam que os atributos ambientais de humanização nas unidades de internação pediátrica não se limitam a questão estética, como cores e decoração com temática infantil. Esta pesquisa ratificou a importância dos quatro componentes de humanização, estudados por Tissot (2016), quais sejam: controle do ambiente, distrações positivas, suporte social e suporte às atividades. Além disso, observou-se a interrelação entre esses componentes, ou seja, um mesmo elemento como o televisor, por exemplo, pode ser considerado uma distração positiva, porém, quando os mecanismos de controle não são eficientes - dificuldade em regular o volume e canais de televisão -, a distração positiva pode se tornar algo estressante e incômodo. O mesmo pode ocorrer na relação com o exterior: quando não há elementos arquitetônicos de proteção solar, prejudicam-se o conforto térmico e lumínico, por exemplo.

Os resultados também evidenciaram que os componentes de humanização podem ser enquadrados em três categorias: elementos arquitetônicos, referência aos reguladores espaciais e elementos de design de interiores, e que estas categorias tiveram maior ou menor frequência nos relatos de acordo com o usuário. As entrevistas mostraram que as necessidades que o ambiente deveria responder eram distintas conforme o tipo de usuário: funcionários, acompanhantes e pacientes. Por exemplo, para os funcionários o componente de suporte às atividades, um dos mais citados, está relacionado principalmente aos aspectos arquitetônicos, tais como o dimensionamento, a organização espacial e mobiliário adequados para a realização do trabalho. Para os pacientes, o componente de distração positiva foi identificado como o mais importante, e está relacionado ao design de interiores e arquitetura. Tanto para os acompanhantes como para os pacientes, notou-se que a forma como o ambiente interfere nos reguladores espaciais - territorialidade, personalização e privacidade também representam importantes atributos que influenciam na humanização.

A seguir serão apresentados os principais atributos ambientais (de acordo com as conclusões desta pesquisa e segundo os participantes), categorizados nos quatro componentes de humanização. 


\section{Controle do ambiente}

Foram identificadas quatro categorias principais nas quais o controle do ambiente pode atuar, as quais estão relacionadas com: os fatores ambientais (conforto acústico, térmico e lumínico); os reguladores espaciais (territorialidade, personalização e privacidade, principalmente); o espaço físico (dimensionamento e organização espacial); aos equipamentos e mobiliário.

O controle sobre os fatores ambientais (como os ruídos, condicionadores de ar, ventilação e iluminação), estão associados ao conforto ambiental dos usuários. Para obter esse controle é importante observar alguns elementos, tais como: superfícies com materiais absorvedores, o tipo de esquadria, cortina, posição do ar condicionado e elementos arquitetônicos como brises, por exemplo. Na pesquisa de campo a presença de ruídos foi identificada como um elemento estressor nos ambientes hospitalares, ocasionada, principalmente, pelo uso compartilhado dos quartos e falta de barreiras físicas entre os leitos, que poderiam reduzir a percepção dos ruídos pelos usuários. Além disso, a implantação dos quartos próxima de áreas ruidosas também contribui para esse tipo de desconforto.

Em relação aos reguladores espaciais observou-se que a clareza dos limites do leito hospitalar é muito importante nos quartos de internação coletivos. Essa definição pode ser estabelecida pela organização espacial que favorece os limites dos espaços individuais. A presença de barreiras físicas entre os leitos, como cortinas, por exemplo, facilita o controle do território, além de possibilitar momentos de privacidade. A possibilidade de personalizar o espaço também demonstrou ser bastante importante, principalmente para os pacientes, pois contribui para a formação de identidade com o lugar e adaptação ao meio. Observou-se que as crianças menores têm uma forte necessidade de manter objetos pessoais próximos, pois existe uma relação de apego e sensação de segurança que esses objetos transmitem.

O controle associado ao espaço físico compreende o dimensionamento adequado, que possibilite a livre movimentação e funcionalidade do ambiente. O conflito gerado pelas dimensões reduzidas do ambiente, dificultando a circulação e utilização do mobiliário, por exemplo, pode levar à invasão do espaço pessoal do outro e ser um causador de estresse durante a hospitalização.

Além do controle sobre o espaço físico, é importante o controle sobre os equipamentos - tomadas e interruptores próximos, regulagem do leito, controle do ar condicionado, televisor - e controle do mobiliário, como armário de uso individual, por exemplo, possibilitando aos usuários utilizar o espaço com conforto e privacidade.

\section{Distrações positivas}

As distrações positivas são um importante componente que auxilia na recuperação dos pacientes internados. Portanto, é necessário considerar as diferentes situações em que podem se encontrar os pacientes - desde os acamados sem mobilidade até aqueles que podem circular e sair do leito -, e incluir diretrizes de forma a atender essas diferenças. Uma das principais fontes de distração positiva identificada pela pesquisa são os recursos audiovisuais, como televisor, celular e tablet. $\mathrm{O}$ acesso a tecnologias mostrou ser fundamental para entretenimento do paciente e, também, do acompanhante. Além dos recursos audiovisuais observou-se a importância da manutenção do brincar no ambiente hospitalar, permitindo que o paciente se distraia e interaja com outras crianças, contribuindo para seu bem-estar e redução da ansiedade.

A presença de iluminação natural combinada com o visual para o exterior foi confirmada como um importante atributo de humanização, por permitir a percepção do dia e da noite, do clima e do que ocorre no exterior. Esse recurso pode ser favorecido através de grandes aberturas, preferencialmente voltadas para cenas da natureza, pois além de estar associada a uma distração positiva, contribui para redução dos níveis de estresse e ansiedade, de acordo com os estudos empíricos e confirmados nesta pesquisa. Além disso, nos quartos de internação a aplicação de cores e revestimentos demonstrou ser um elemento significativo, uma vez que as cores possuem um efeito fisiológico sobre os usuários. $\mathrm{N}$ investigação realizada observou-se que os quartos em tons neutros e com poucos elementos decorativos foram caracterizados como monótonos e com poucos elementos com os quais os pacientes se identificavam, enquanto a presença de diferentes tonalidades e de cores estimulantes foi associada a uma maior identidade, contribuindo para o processo de adaptação hospitalar dos pacientes.

\section{Suporte social}

Destaca-se a importância da presença do acompanhante para o paciente internado, bem como a possibilidade de receber visitas. Na pesquisa de campo, verificou-se que os locais ao ar livre e em contato com a natureza 
eram frequentemente utilizados pelas famílias, pela sua ambiência mais agradável e possibilidade de maior privacidade nas conversas e interações sociais. Dessa forma, é importante que esses espaços sejam equipados com mobiliário que favoreça as relações sociais e oportunize diferentes atividades, como brincadeiras, por exemplo.

Além disso, destaca-se que para os pacientes, principalmente as crianças, é muito importante a presença de ambientes como a sala de recreação e a sala de aula, pois possibilitam a interação com outras crianças. Dessa forma, as dificuldades proporcionadas pela hospitalização podem ser amenizadas, atuando como distração positiva e também suporte social. Considerando novamente a situação do paciente, é importante que o quarto de internação também proporcione e favoreça as relações sociais, principalmente para os pacientes acamados.

\section{Suporte às atividades}

O componente de suporte às atividades foi incluído nesta pesquisa e confirmou-se sua importância principalmente para a realização do trabalho pelos funcionários. Este componente está associado principalmente ao dimensionamento e layout adequados, que contribuem para o desenvolvimento das atividades com conforto e segurança.

Dentre as atividades desempenhadas no quarto de internação, observou-se alguns aspectos que estão ligados diretamente ao conforto do mobiliário, seu dimensionamento e ergonomia. Dentre esses aspectos, destaca-se o conforto da cama hospitalar e da poltrona do acompanhante, identificados como fundamentais para satisfação dos usuários, pois interferem diretamente na qualidade do sono e, também, na recuperação do paciente, visto que grande parte das internações duram semanas e até mesmo meses.

Para os funcionários o dimensionamento apropriado do espaço físico e a presença de mobiliário de apoio foram levantados como primordiais para o bom atendimento e realização de procedimentos no leito. A dificuldade de acesso ao paciente - devido as dimensões reduzidas do ambiente e conflito de espaço com a poltrona do acompanhante -, falta de mobiliário para apoiar os objetos e iluminação inadequada foram relacionados a uma maior ansiedade e insegurança por parte dos funcionários.

A qualidade da iluminação artificial também foi identificada como essencial, pois a iluminação deve proporcionar diferentes tipos de atividades, como: exame, repouso, lazer e vigília. Para tanto, é necessário prever diferentes tipos de iluminação, e o acionamento dessas diferentes luminárias deve estar posicionado em local de fácil acesso e alcance, propiciando a execução das atividades com segurança e conforto. Além disso, essas características estão relacionadas ao componente de controle do ambiente, por proporcionar maior autonomia aos usuários.

\section{DIRETRIZES PROJETUAIS}

Tendo como base os principais atributos ambientais de humanização segundo os resultados da pesquisa, são sugeridas diretrizes projetuais para o quarto de internação pediátrica. $O$ exemplo apresenta diretrizes para quartos de uso coletivo, configurado em pares de leitos. Verificou-se que esta é a realidade da maior parte dos hospitais públicos brasileiros: quartos pediátricos coletivos, que incluem diferentes faixas etárias e gêneros, devido à alta demanda por atendimentos e necessidade de otimização do espaço. Dessa forma, este projeto buscou integrar essa realidade, considerando as necessidades específicas de cada grupo de usuários, e baseado na preferência por quartos coletivos pelos pacientes, conforme resultado da pesquisa de campo.

O dimensionamento teve como principal referência a NBR 9050 (ABNT, 2020), pois verificou-se que as medidas mínimas exigidas na RDC 50 nem sempre eram compatíveis com as medidas de circulação estabelecidas pela norma de acessibilidade. Por compreender que o hospital atende pacientes em diferentes condições físicas e de locomoção entende-se que o ambiente construído deve atender com conforto e segurança a todos esses usuários. Por isso, foram adotadas medidas que permitem o giro de $360^{\circ}$ de usuário de cadeira de rodas no quarto e banheiro de internação. É sugerido que a circulação central tenha 1,50m, de forma a atender a acessibilidade, e facilitar a entrada e saída das cama-maca quando necessário. Além disso, recomenda-se que a distância entre leitos paralelos seja de $1,20 \mathrm{~m}$, e a distância do leito até a parede de no mínimo 1,10m. Ressalta-se que a norma vigente adota como distância mínima entre leitos paralelos 1,0m e a distância mínima entre o leito e parede $0,50 \mathrm{~m}$. O layout foi configurado de modo a permitir o livre acesso ao paciente pelos funcionários por pelo menos um dos lados e do outro estão dispostos o suporte de soro e poltrona do acompanhante. Destaca-se, ainda, ser essencial a clara delimitação física de quatro áreas 
principais, que foram denominadas: zona de suporte, zona do paciente, zona de lazer e zona de higiene (indicadas nas Figura 1).

Figura 1: Planta baixa do quarto e banheiro de internação com indicação das quatro zonas.

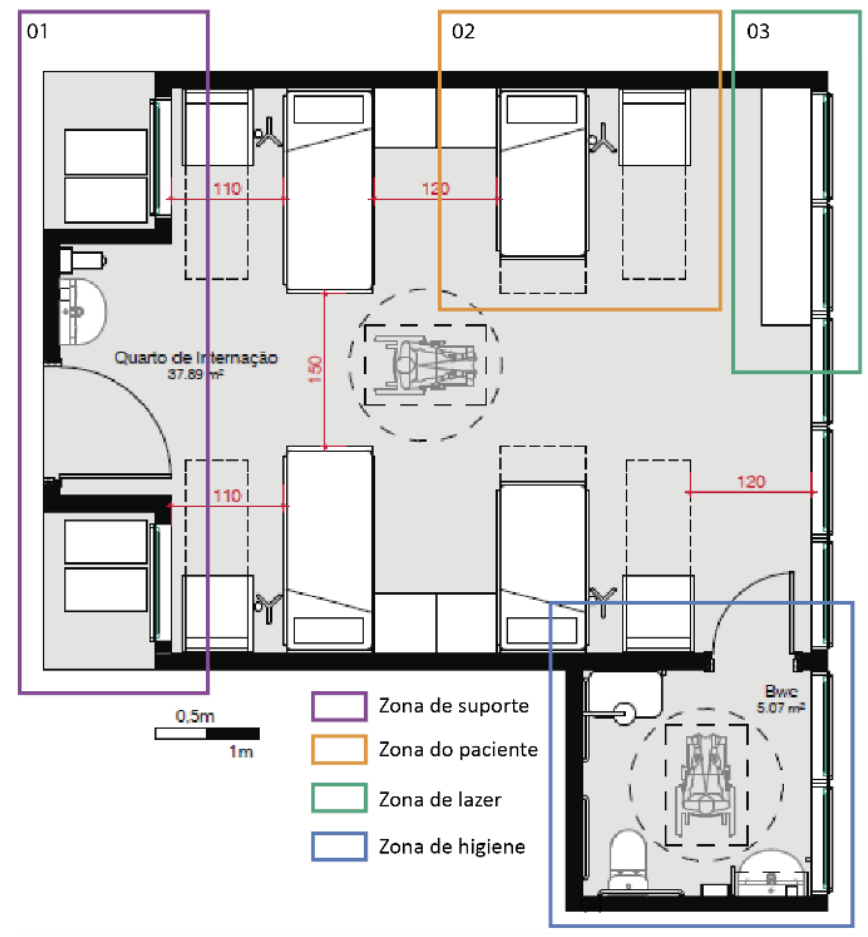

Fonte: Elaborado pela autora.

A zona de suporte é destinada ao suporte às atividades e abrange o mobiliário e equipamentos de uso dos funcionários, localizados próximos do acesso ao quarto. Para isso, é proposta uma antessala para alocação do lavatório, de forma a facilitar a higienização das mãos pelo corpo técnico sem invadir o espaço físico da zona do paciente. Essa área deverá prover papel toalha, saboneteira, álcool gel, lixeira. O revestimento das paredes deve ser cerâmico. Além disso, foi incluído um espelho para o conforto dos acompanhantes. Para os procedimentos realizados no leito é sugerida a utilização de mesas de apoio móveis, para que não haja conflito de uso e diminuição da circulação interna no quarto (Figura 2). Essas mesas ficariam guardadas em recuos no corredor geral da unidade, com proximidade do acesso ao quarto. Na zona do paciente também serão apresentados outros recursos que correspondem ao suporte às atividades pelos funcionários no leito hospitalar.

Figura 2: Imagem do quarto de internação, com destaque para os elementos da zona de suporte.

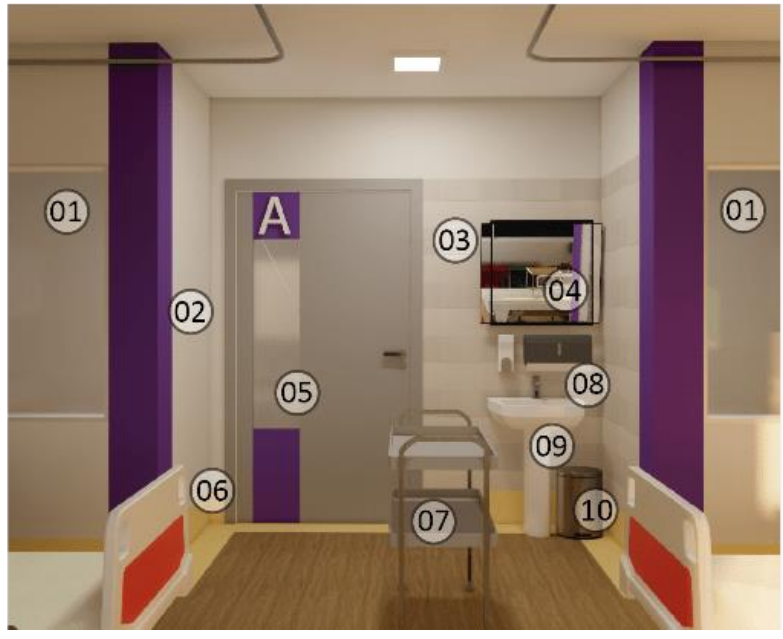

Fonte: Elaborado pela autora.
(01) Vidro fixo corredor

02 Antessala

(03) Revestimento cerâmico

(04) Espelho inclinado

05 Porta com visor

(06) Contraste do rodapé

(07) Mesa de procedimentos

08 Papel toalha, saboneteira, álcool gel

09) Lavatório

(10) Lixeiro com pedal 
Para a zona do paciente buscou-se individualizar o espaço físico de cada leito através de um conjunto de mobília associada, composto pela cama hospitalar, poltrona do acompanhante e armário individual, com o intuito de favorecer a formação de territórios (Figura 3). Esse conjunto de mobiliário pode ser isolado através de cortinas de trilho, para os momentos de maior privacidade, contribuindo também para diminuição da percepção dos níveis de ruídos, através do isolamento visual das fontes sonoras.

Sugere-se a inclusão de armários individuais, remetendo a aparência residencial, como forma de incentivar a personalização do espaço pelos pacientes. Para isso, foi incluído um mural de recados no leito e quadro de imã para colar fotos e desenhos. O armário comporta espaço para guarda dos pertences do paciente e do acompanhante e, também, é previsto um nicho para armazenar uma mesa de refeições compacta e retrátil.

Em relação ao conforto do paciente e dos acompanhantes sugere-se que sejam adotadas camas-macas com regulagem mecânica, evitando transferências de pacientes, e que as poltronas sejam do tipo sofá-cama. Para que haja um maior controle do ambiente por parte dos usuários, cada leito possui um conjunto de equipamentos dispostos em locais de fácil alcance como: campainha de enfermagem, tomadas e interruptor para acionamento da iluminação artificial. É proposto iluminação indireta no teto e iluminação de vigília para o funcionário chegar até o leito e realizar o atendimento no período noturno. Além disso, propõe-se uma luminária articulada próxima do leito para as atividades de leitura, por exemplo, e iluminação geral do quarto, com a possibilidade de graduar a luminância através de um dimmer. Demais elementos, como as instalações de gases medicinais, suporte de soro e iluminação de vigília, são destinados ao trabalho dos funcionários. Recomenda-se que esses equipamentos e instalações estejam dispostos em local de fácil acesso - facilitando o trabalho da equipe -, e que a iluminação de vigília esteja instalada na parede a $50 \mathrm{~cm}$ do piso acabado.

Figura 3: Imagem do quarto de internação, com destaque para os elementos da zona do paciente.

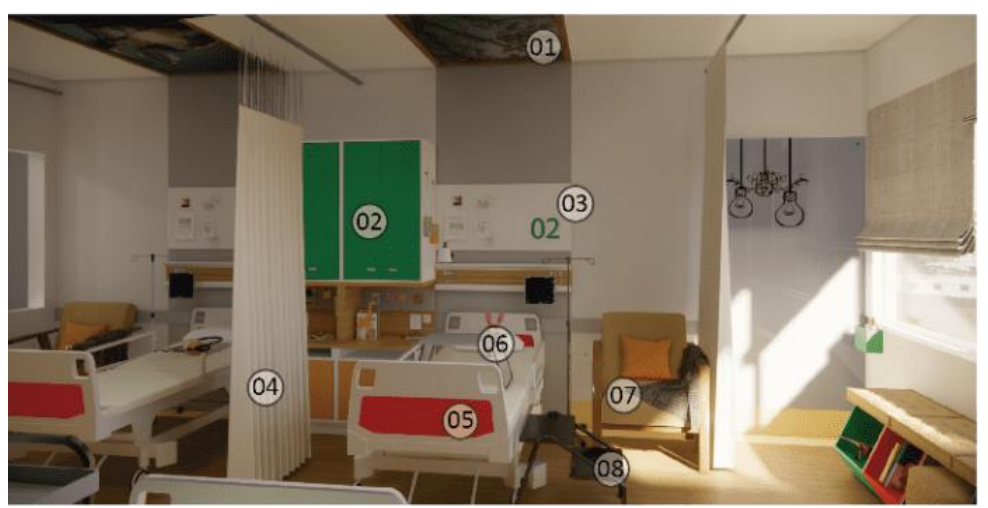
(01) Iluminação indireta
(02) Armário individual
(03) Identificação do leito
(04) Cortina de trilho
(05) Cama-maca
(06) Mesa de refeições
(07) Poltrona do acompanhante
(08) Escada de 2 degraus
(09) Quadro de recados
(10) Suporte de soro
(11) Luminária articulada
(12) Instalações gases medicinais
(13) Bate-maca
(14) Campainha, interruptor e tomadas
(15) Quadro de imã
(16) Iluminação de vigília

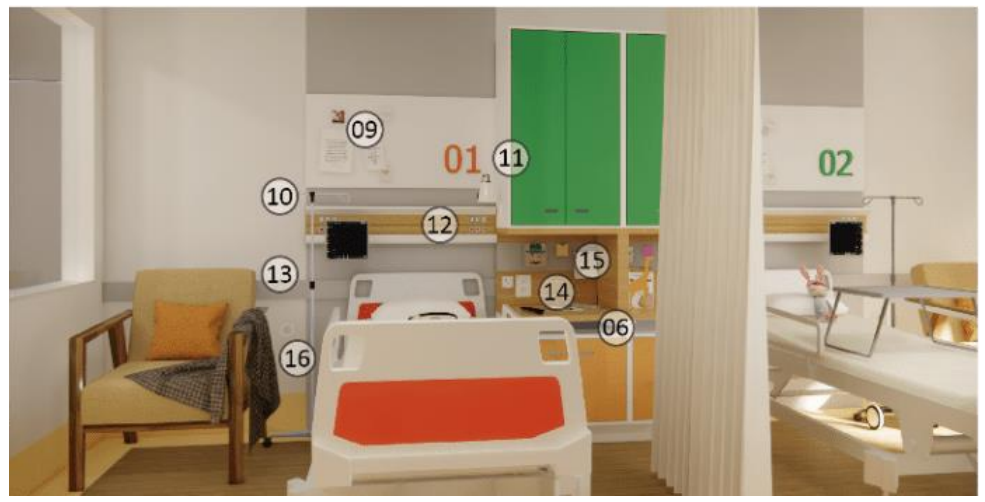

Fonte: Elaborado pela autora.

Para zona de lazer são propostas diretrizes que visam o atendimento do paciente que pode sair do leito e utilizar os espaços de lazer do quarto e, também, os pacientes acamados, com distrações positivas que envolvem a área do leito hospitalar. Dessa forma, é proposta uma área dentro do quarto que promova o suporte social e interação entre os pacientes, acompanhantes e visitas (Figura 4). Essa área foi localizada próxima de grandes aberturas, com peitoril baixo e mecanismos de proteção solar: brises e cortinas. Como forma de promover esse suporte social é proposto mobiliário para guarda de brinquedo, pufes, banco estofado e um quadro branco para os pacientes escreverem, desenharem e criarem brincadeiras. 
Além disso, foram incluídos outros elementos que podem promover distração positiva como: presença de vidro fixo e porta com visor nos corredores, para controle dos funcionários e distração dos pacientes, também passíveis de controle através de cortinas; pintura no teto de cenas da natureza ou ilustrações, contornada por iluminação indireta; e presença de televisores em posição favorável para todos os leitos. Em relação as cores e revestimentos é sugerida a combinação de cores tríades, compostas por diferentes tonalidades do círculo cromático, com cores quentes e frias. É importante que essas cores sejam aplicadas de forma moderada, para que não haja cansaço visual gerado por grandes áreas revestidas com cores estimulantes.

Figura 4: - Imagem do quarto de internação, com destaque para os elementos da zona de lazer.

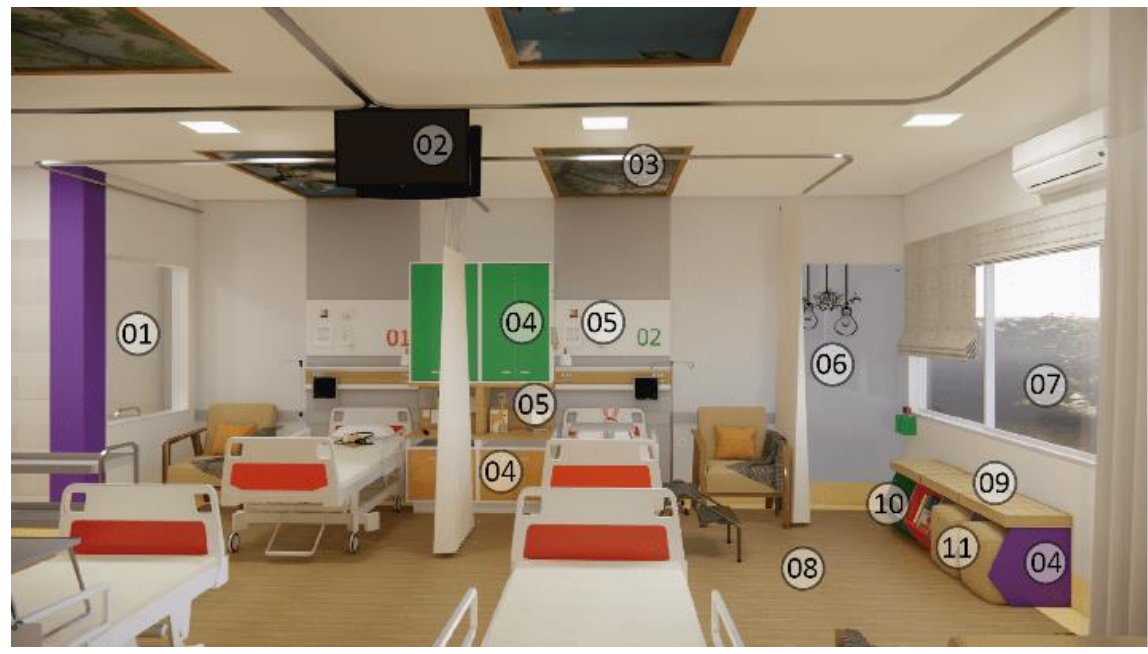

(01) Vidro fixo corredor

(02) Posição central do televisor

(03) Pintura no teto

(04) Cores tríades

(05) Personalização do leito

(06) Quadro branco

(07) Amplas aberturas, peitoril baixo

(08) Piso vinílico madeirado

(09) Estofado

(10) Caixa de brinquedos

(11) Pufes

Fonte: Elaborado pela autora.

Quanto à zona de higiene, recomenda-se que cada quarto possua um banheiro exclusivo de uso do paciente e que este atenda a norma de acessibilidade em relação ao dimensionamento, localização e tipo de equipamentos. Essa diretriz é baseada na situação dos pacientes que, em geral, necessitam de ajuda de terceiros nos cuidados de higiene, o que exige um dimensionamento adequado dos banheiros. Além disso, sugere-se que os banheiros possuam algumas características que proporcionem suporte às atividades, como por exemplo: nicho dentro do box do chuveiro para apoiar os objetos durante o banho, e instalado em altura adequada ao paciente e ao acompanhante; e a presença de prateleira e espelho próximos do lavatório, favorecendo as atividades de cuidado e higiene (Figura 5).

Figura 5: - Imagem do quarto de internação, com destaque para os elementos da zona de higiene.



Fonte: Elaborado pela autora.
(01) Espelho inclinado

(02) Papel toalha

(03) Cabideiro

(04) Saboneteira

(05) Prateleira

(06) Barras de apoio

(07) Nicho box

(08) Suporte papel higiênico

(09) Alarme de emergência

(10) Banco 
As quatro zonas (de suporte, do paciente, de lazer e de higiene) foram criadas para ilustrar e diferenciar atividades e características específicas para cada setor. Destaca-se a importância de individualizar os limites físicos de cada leito e destinar locais específicos para o suporte às atividades dos funcionários. Além disso, é importante buscar bom aproveitamento do espaço, que pode, por exemplo, prever uma ambiência agradável junto às janelas, destinadas ao suporte social e interação entre os usuários no quarto.

\section{CONSIDERAÇÕES FINAIS}

Dentre as principais contribuições deste trabalho, destaca-se a inter-relação entre os quatro componentes de humanização: suporte social, distrações positivas, controle do ambiente e suporte às atividades. Evidenciouse que a garantia da qualidade de um componente de humanização depende do estabelecimento de uma relação de equilíbrio entre os demais componentes, para que as características ambientais em conjunto estejam harmonizadas com o contexto e as necessidades dos usuários. Além disso, esta pesquisa reforça a influência de determinados componentes de humanização para a percepção de bem-estar de acordo com o tipo de usuário.

Além disso, a partir das diretrizes projetuais se pode refletir sobre as exigências mínimas estabelecidas pela legislação vigente. No estudo de caso verificou-se a importância da clara delimitação física dos leitos nos quartos coletivos, essenciais para manutenção da privacidade e territorialidade e, para isso, constatou-se que as dimensões mínimas, por exemplo, necessitam ser revisadas, para que além desses aspectos, atenda também os princípios de acessibilidade. Dessa forma, a definição das diretrizes projetuais e apresentação de um projeto aplicando essas diretrizes possibilitou a espacialização dos anseios dos usuários e das conclusões da pesquisadora. A espacialização também proporcionou a reflexão sobre as exigências mínimas exigidas pela legislação, principalmente no quesito dimensionamento.

Através de um comparativo de metragem quadrada, verificou-se por exemplo, que a proposta acrescenta cerca de $10 \mathrm{~m}^{2}$ no quarto de internação, se comparado com a média de metragem quadrada dos seis quartos avaliados no estudo de caso, no valor de $27 \mathrm{~m}^{2}$. A legislação adota uma média de $6 \mathrm{~m}^{2}$ por leito e na proposta a média estabelecida foi de $9,5 \mathrm{~m}^{2}$ por leito. Esse acréscimo de área possibilitou a criação de uma zona de lazer dentro do quarto - possibilitando suporte social e distrações positivas -, além de proporcionar maior controle e conforto aos pacientes e acompanhantes, como também favorecer as atividades de trabalho dos funcionários.

As diretrizes projetuais apresentadas reforçam a importância da humanização nos ambientes hospitalares, demonstrando que é possível humanizar os espaços através da arquitetura, em intervenções na organização espacial, bem como nos elementos de design de interiores. Neste sentido, esta pesquisa ratifica os benefícios da humanização na percepção de bem-estar dos usuários e na recuperação dos pacientes.

\section{AGRADECIMENTOS}

As autoras agradecem à Coordenação de Aperfeiçoamento de Pessoal de Nível Superior (CAPES), à Universidade Federal de Santa Catarina, ao Programa de Pós-Graduação em Arquitetura e Urbanismo da UFSC, ao Hospital Infantil Joana de Gusmão e a todos os entrevistados que contribuíram para o desenvolvimento desta pesquisa.

\section{REFERÊNCIAS}

ASSOCIAÇÃO BRASILEIRA DE NORMAS TÉCNICAS (ABNT). NBR 9050: acessibilidade a edificações, mobiliário, espaços e equipamentos urbanos. Rio de Janeiro, 2020.

BARDIN, L. Análise de conteúdo. São Paulo: Edições 70, 2011.

BRASIL. Ministério da Saúde. RDC o 50, de 21 de fevereiro de 2002. Dispõe sobre o Regulamento Técnico para planejamento, programação, elaboração e avaliação de projetos físicos de estabelecimentos assistenciais de saúde. Diário Oficial da República Federativa do Brasil. Brasília, 20 de mar. de 2002.

BERGAN C., BURSZTYN I., SANTOS M. C. O., TURA L. F. R. Humanização: representações sociais do hospital pediátrico. Rev Gaúcha Enferm [Internet]. pp. 656-661, 2009. Disponível em: http://www.scielo.br/pdf/rgenf/v30n4/ a11v30n4.pdf.

CAVALCANTI, P. B. Qualidade da iluminação em ambientes de internação hospitalar. Dissertação (Mestrado). Programa de Pós-Graduação em Arquitetura. Universidade Federal do Rio Grande do Sul. Porto Alegre, 2002. 
CAVALCANTI, P. B. A Humanização de Unidades Clínicas de Hospital-Dia: vivência e apropriação pelos usuários. Tese (Doutorado). Programa de Pós-Graduação em Arquitetura. Universidade Federal do Rio de Janeiro. Rio de Janeiro, 2011.

COAD J., COAD N. Children and young people's preference of thematic design and colour for their hospital environment. J Child Health Care [Internet], pp. 33-48, 2008. Disponível em : http://chc.sagepub.com/ content/12/1/33.full.pdf. Acesso em 03/05/2020.

FELIPPE, M. L. Ambiente físico e linguagem ambiental no processo de restauração afetiva do estresse em quartos de internação pediátricos. Tese. (Doutorado). Tecnologia da Arquitetura. Departamento de Arquitetura, Universidade de Ferrara. Ferrara, 2015

NEUFERT, E. Arte de projetar em Arquitetura. Barcelona: Gustavo Gili, 2008.

OLIVEIRA, S. S. G., DIAS, M. G. B., \& ROAZZI, A. O lúdico e suas implicações nas estratégias de regulação das emoções em crianças hospitalizadas. Psicologia, Reflexão e Crítica, pp.1-13, 1998.

RHEINGANTZ, P. A. et al. Observando a qualidade do lugar: procedimentos para a avaliação pós-ocupação. Rio de Janeiro: ProARQ/FAU/UFRJ, 2009.

ROCHA, J. L. Humanização de maternidades públicas: um estudo sobre a arquitetura das enfermarias de alojamento conjunto. Dissertação (Mestrado). Programa de Pós-Graduação em Arquitetura, Centro Tecnológico, Universidade Federal de Santa Catarina, Florianópolis, 2010.

ROLLINS J. A. The influence of two hospitals' designs and policies on social interaction and privacy as coping factors for children with cancer and their families. J Pediatr Oncol Nurs. 2009, pp. 340-53. Disponível em: http://jpo.sagepub.com/content/26/6/340.full.pdf. Acesso em 03/05/2020.

SANOFF, H. Visual Research Methods in Design. New York: Van Nostrand Reinhold, 1991.

SILVA, D. F.; CORRÊA, I. Reflexão sobre as vantagens, desvantagens e dificuldades do brincar no ambiente hospitalar. REME - Revista Mineira de Enfermagem, Belo Horizonte, p.37-42, 2010.

TISSOT, J. T. Definição de elementos ambientais essenciais para a humanização em quartos de internação. Dissertação (Mestrado). Programa de Pós-Graduação em Arquitetura e Urbanismo, Centro Tecnológico, Universidade Federal de Santa Catarina, Florianópolis, 2016. Disponível em: http://www.bu.ufsc.br/teses/PARQ0233-D.pdf. Acesso em 03/05/2020.

THORNE, R. Using visual methods to focus user's response in predesign and postoccupancy research. In: BAIRD, George et al. (Edit.) Building evaluation techniques. New York: McGraw-Hill, p. 123-128, 1995.

ULRICH, R. S. Effects of healthcare Interior Design on Wellness: theory and recent scientific research. In: SYMPOSIUM ON HEALTHCARE DESIGN, 4. In : Malberry, S. O. (Ed.) Innovations in healthcare design: selected presentations from the first five symposia on healthcare design. New York: John Wiley \& Sons, pp. 97-109, 1995.

ULRICH, R. S. Effects of healthcare environmental design on medical outcomes. In: A DILANI (Ed.) Design and Health: Proceedings of the Second International Conference on Health and Design. Stockholm, Sweden: Svensk Byggtjanst, pp. 49-59, 2001.

ULRICH, R. S.; ZIMRING, C. ; QUAN, X.; JOSEPH, A. The environment's impact on stress. In: S. MARBERRY (Ed.), Improving Healthcare with Better Building Design. Chicago: Health Administration Press, pp. 37-61, 2006.

VASCONCELOS, R. T. B. Humanização de ambientes hospitalares: características arquitetônicas responsáveis pela integração interior/exterior. Dissertação (Mestrado). Programa de Pós-Graduação em Arquitetura, Centro Tecnológico, Universidade Federal de Santa Catarina, Florianópolis, 2004. Disponível em: http://www.tede.ufsc.br/teses/PARQ0007.pdf Acesso em 03/05/2020.

ZEISEL, J. Inquiry by design: tools for environment behavior research. New York: Cambridge University Press, 2006.

NOTA DO EDITOR (*): O conteúdo do artigo e as imagens nele publicadas são de responsabilidade do(s) autor(es). 